\title{
Anticorpos contra vírus de galinha em cracídeos
}

\author{
Detection of antibodies against commercial poultry viruses in cracids
}

\author{
Helton Fernandes dos Santos ${ }^{\mathrm{I}}$ Maristela Lovato Flores ${ }^{\mathrm{I}}$ Valéria Maria Lara ${ }^{\mathrm{II}}$ \\ Iara Maria Trevisol ${ }^{\mathrm{II}}$ Luciane Teresinha Lovato ${ }^{\mathrm{II}}$ *
}

\begin{abstract}
Os cracídeos são Galliformes silvestres das Américas. Com o objetivo de investigar a presença de anticorpos contra vírus de galinhas em cracídeos, foram coletadas 51 amostras de soro de 10 diferentes espécies dessas aves. Esses animais eram mantidos em criatórios conservacionistas e zoológicos nos Municípios de Santa Maria, Soledade, Passo Fundo, Sapucaia, Gravataí, Viamão e Três Coroas, Estado do Rio Grande do Sul, Brasil. Anticorpos neutralizantes foram detectados em 5,9\% (3/51) do total de amostras testadas contra o vírus da bronquite infecciosa das galinhas, 15,7\% (8/51) contra o reovírus aviário e 35,3\% (18/ 51) contra o vírus da doença infecciosa da bolsa. Todas as amostras foram negativas para o vírus da bouba aviária no teste de IDGA. A detecção de anticorpos para vírus de aves comerciais sugere que os cracídeos podem ser susceptíveis à infecção por esses vírus.
\end{abstract}

Palavras-chave: bronquite infecciosa das galinhas, bouba aviária, doença infecciosa da bolsa, reovírus aviário, Cracidae, aves silvestres, cativeiro, anticorpos.

\section{ABSTRACT}

The cracids are wild Galliformes native from the Americas. Fifty one serum samples were collected from individuals of 10 different species of cracids in order to obtain information regarding to the antibody status of different viruses.
These birds were kept in shelters and zoos localized in Santa Maria, Soledade, Passo Fundo, Sapucaia, Gravataí, Viamão and Três Coroas counties, in the Rio Grande do Sul State, Brazil. Neutralizing antibodies were detected in the individuals serum from different species specific referring to infectious bronchitis virus in $5.9 \%(3 / 51)$ of the samples, to avian reovirus in $15.7 \%$ (8/51) and, to infectious bursal disease virus in 35.3\% (18/51). All samples were negative for fowlpox virus, as measured by IDGA test. The detection of commercial poultry viruses antibodies suggests that cracids could be susceptible to infection by those viruses.

Key words: infectious bronchitis, fowlpox, infectious bursal disease, reoviruses, Cracidae, wild birds, captive wildlife, antibodies.

Os cracídeos são aves silvestres que habitam as florestas da América Latina (SICK, 1997). Existem cinquenta espécies de cracídeos classificados em 11 gêneros na família Cracidae, ordem Galliformes. No Brasil, já foram identificadas 25 espécies, e entre as mais conhecidas estão os mutums, os araquãs, os jacus e as jacutingas (EVÊNCIO, 2006). Há pouca informação científica sobre a microbiologia dessas espécies, principalmente no que se refere a agentes de doenças infecciosas. De acordo com EVÊNCIO (2006), esses

\footnotetext{
'Departamento de Medicina Veterinária Preventiva, Centro de Ciências Rurais (CCR), Universidade Federal de Santa Maria (UFSM), Santa Maria, RS, Brasil.

"Departamento de Microbiologia e Parasitologia, Centro de Ciências da Saúde (CCS), UFSM. Av. Roraima, nº. 1000, Camobi, 97105-900, Santa Maria, RS, Brasil. E-mail: llovato@smail.ufsm.br.*Autor para correspondência.

II'Centro Nacional de Pesquisa de Suínos e Aves (CNPSA), Empresa Brasileira de Pesquisa Agropecuária (EMBRAPA), Concórdia, SC, Brasil.
} 
galináceos silvestres são suscetíveis a uma variedade de agentes virais, bacterianos, fúngicos e parasitários; entretanto, não há descrição desses agentes.

A presença do vírus ou dos anticorpos contra os vírus que causam doenças em aves domésticas já foi relatada em outras espécies silvestres. Dentre estes, podem ser citados os vírus da doença infecciosa da bolsa (IBDV), o reovírus aviário (ARV), a bronquite infecciosa das galinhas (IBV) e o vírus da bouba aviária (FPV) (LUKERT \& SAIF, 2003). O IBDV causa lesões principalmente na bolsa cloacal de aves jovens, levando a manifestações clínicas de diarréia e desidratação (NIBERT \& SCHIFF, 2001); artrite e tenossinovite são as manifestações primárias do ARV (GOUVEA \& SCHNITZER, 1982). O IBV é o agente etiológico de uma enfermidade aguda e altamente contagiosa, afetando de forma mais acentuada os sistemas respiratório e urogenital (CAVANAGH \& NAQI, 2003), e o FPV causa lesões cutâneas nodulares, que, mais raramente, atingem a cavidade oral e o trato respiratório superior (LÜSCHOW et al., 2004).

A falta de informações sobre a circulação de vírus de galinhas na população de Cracídeos direcionou este estudo. Foram coletadas amostras de soro de 51 cracídeos, agrupados em 10 espécies (Tabela 1), durante o ano de 2007. Essas aves eram mantidas cativas em cinco criatórios conservacionistas e três zoológicos do Estado do Rio Grande do Sul, Brasil; credenciados pelo Instituto Brasileiro do Meio Ambiente e dos Recursos Naturais Renováveis (IBAMA). Os animais estudados apresentavam-se clinicamente sadios e não tinham histórico de vacinação. A coleta das amostras foi oficialmente autorizada pelo IBAMA (SISBIO no. 11629-1) e foi realizada a partir das normas desse Instituto.
Células primárias de embrião de galinha (FEG) e de rim de pintos (CRP) de um dia foram utilizadas para a produção do estoque viral e a realização dos testes de soroneutralização. As células FEG foram utilizadas para os vírus ARV e IBDV, enquanto a CRP foi utilizada para o IBV. As células foram preparadas e cultivadas como descrito por SANTOS et al (2008). As cepas virais Beaudette do IBV, S1133 do ARV e GT-1 do IBDV e o antígeno do FPV foram cedidos pela Empresa Brasileira de Pesquisa Agropecuária, Centro Nacional de Pesquisa em Suínos e Aves (Concórdia, Santa Catarina (SC)).

O soro para os testes sorológicos foi obtido por meio de coleta de sangue da veia ulnar, inativado a $56^{\circ} \mathrm{C}$ e armazenado a $-20^{\circ} \mathrm{C}$ até ser testado. As amostras de soro provenientes das diferentes espécies de cracídeos foram testadas pela técnica de soroneutralização (SN) para IBV, IBDV e ARV; e com a técnica de imunodifusão em gel de ágar (IDGA) para FPV. A detecção de anticorpos contra esses vírus foi realizada conforme a metodologia descrita por ROMERO(1986).

Anticorpos contra IBV, IBDV e ARV foram detectados nas amostras de soro da população de cracídeos testada; entretanto, todas as amostras apresentaram-se negativas para a presença de anticorpos contra o FPV (Tabela 1).

O vírus da bouba aviária (FPV) deixou de ser um problema para a indústria avícola há bastante tempo, e o uso da vacina mantém a situação sob controle. Contudo, essa doença viral tem sido descrita em várias espécies de aves, com maior frequência entre os Passeriformes (HUKKANEN et al., 2003). De certa maneira, a ausência de anticorpos contra FPV entre os

Tabela 1 - Prevalência de anticorpos contra o vírus da bronquite infecciosa das galinhas (IBV), reovírus aviário (ARV), vírus da doença infecciosa da bolsa (IBDV) e vírus da bouba aviária (FPV) em cracídeos cativos.

\begin{tabular}{|c|c|c|c|c|c|}
\hline \multirow[b]{2}{*}{ Nome vulgar } & \multirow[b]{2}{*}{ Nome científico } & \multicolumn{3}{|c|}{-----------------Soroneutralização----------------- } & \multirow{2}{*}{$\begin{array}{c}\text { IDGA* }^{*} \\
\text { FPV }\end{array}$} \\
\hline & & IBV & ARV & IBDV & \\
\hline Araquã & Ortalis guttata & $0 / 4$ & $0 / 4$ & $3 / 4$ & $0 / 4$ \\
\hline Jacu & Penelope obscura & $0 / 8$ & $2 / 8$ & $3 / 8$ & $0 / 8$ \\
\hline Jacupemba & Penelope superciliaris & $0 / 4$ & $0 / 4$ & $1 / 4$ & $0 / 4$ \\
\hline Jacupara & Pipile pipile & $0 / 3$ & $0 / 3$ & $1 / 3$ & $0 / 3$ \\
\hline Jacutinga & Pipile jacutinga & $0 / 5$ & $2 / 5$ & $1 / 5$ & $0 / 5$ \\
\hline Mutum-cavalo & Mitu tuberosa & $2 / 17$ & $2 / 17$ & $4 / 17$ & $0 / 17$ \\
\hline Mutum-do-sudeste & Crax blumenbachii & $0 / 1$ & $0 / 1$ & $1 / 1$ & $0 / 1$ \\
\hline Mutum-penacho & Crax fasciolata fasciolata & $1 / 4$ & $0 / 4$ & $2 / 4$ & $0 / 4$ \\
\hline Mutum-pinima & Crax fasciolata pinima & $0 / 3$ & $2 / 3$ & $2 / 3$ & $0 / 3$ \\
\hline Urumutum & Nothocrax urumutum & $0 / 2$ & $0 / 2$ & $0 / 2$ & $0 / 2$ \\
\hline Total & & $3 / 51$ & $8 / 51$ & $18 / 51$ & $0 / 51$ \\
\hline
\end{tabular}

* IDGA: imunodifusão em gel de agar. 
cracídeos não era um resultado esperado. Principalmente se for levado em consideração o fato de que esse vírus é muito resistente no meio ambiente e é comumente observado em populações de galinhas não vacinadas (TRIPATHY \& REED, 2003). Além disso, existe também a possibilidade de aves vacinadas com vacinas vivas servirem como fonte de infecção pelo vírus, cuja transmissão, nesse caso, pode ocorrer por meio de vetores hematófagos, tais como mosquitos.

Por outro lado, a bronquite infecciosa das galinhas é uma das enfermidades virais mais importantes para a indústria avícola (CAVANAGH \& NAQI, 2003). Várias cepas têm causado doença nos tratos respiratório e urinário, além de causarem miopatias em galinhas, faisões e codornas (REED \& JACK, 2003). No presente estudo, observou-se que apenas mutuns provenientes de um único estabelecimento foram positivos para a presença de anticorpos contra IBV (Tabela 1), com títulos que variaram entre 40 e 160 (dados não apresentados). Um aspecto relevante nesse caso é o fato de que essas aves estavam alojadas próximas a Galliformes domésticos (galinhas, perus e faisões), que se encontravam encerrados em um espaço localizado a aproximadamente 30 metros de distância.

A mais alta prevalência de anticorpos foi observada contra o IBDV (35.3\%), observando-se também um maior número de espécies positivas. Anticorpos contra o vírus foram detectados em nove das 10 espécies examinadas (Tabela 1), com títulos variando entre 40 e 5120 (dados não apresentados) e, no mínimo, uma ave foi positiva em cada zoológico ou criatório (Tabela 1). Embora a galinha seja a única espécie conhecida que desenvolve a doença clínica (LUKERT \& SAIF, 2003), anticorpos contra esse vírus já foram detectados no soro de pinguin-rei (Aptenodytes patagonicus) da Antártica (CLERC et al., 2002) e faisões (LUKERT \& SAIF, 2003).

Os dados sorológicos isolados não são suficientes para determinar a importância do IBDV para os cracídeos. A presença de anticorpos no soro pode significar que essas aves são susceptíveis ao vírus e capazes de formar uma resposta imune contra ele, mas não se pode descartar totalmente a possibilidade de uma reação cruzada com outros antígenos. Outra possibilidade seria o contato dessas aves com aves comerciais vacinadas com vacina viva contra a doença infecciosa bursal; entretanto, apenas uma parcela dessas aves estava alojada próxima de galinhas. A alta prevalência de anticorpos contra o IBDV nas espécies testadas pode contribuir como argumento para a primeira hipótese, principalmente se comparados esses resultados com estudos realizados em outras espécies, tais como o pinguin de Galápagos (Spheniscus mendiculus), no Equador (TRAVIS et al., 2006), e petréis gigantes (Macronectes giganteus), na Argentina (UHART et al., 2003), que resultaram soronegativas para esse vírus.

Cracídeos poderiam ter em tese algum papel na epidemiologia da doença infecciosa bursal, tendo em vista que cepas do IBDV podem ser carreadas por perus, embora não patogênicas para galinhas (LUKERT \& SAIF, 2003). Entretanto, no Brasil, as medidas de biosseguridade implementadas pela avicultura industrial seriam provavelmente suficientes para evitar problemas. Convém destacar que o mutum-de-Alagoas (Mitu mitu) está extinto da natureza e outras espécies de cracídeos encontram-se ameaçadas.

Anticorpos contra o ARV foram detectados em quatro das espécies de cracídeos (Tabela 1) provenientes de cinco diferentes criatórios, com título variando entre 20 e 1280 (dados não apresentados). O ARV já foi isolado de várias espécies de aves silvestres, algumas vezes associado à alta mortalidade, como relatado por DOCHERTY (1994), em becadas americanas (Scolopax minor), nos Estados Unidos, e por HOLLMEN et al. (2002), em aves aquáticas, na Finlândia. O papel do vírus na doença foi evidenciado pelo isolamento e por estudos sorológicos realizados durante o período de mortalidade, que demonstrou que 86\% das aves mortas tinham anticorpos contra o ARV (HOLLMEN et al., 2002). Nesse caso, como ocorreu com os outros vírus citados neste artigo, deve-se levar em consideração a existência e aplicação de vacinas vivas em aves comerciais, que pode servir de fonte de vírus para outras aves.

Este é possivelmente o primeiro relato de estudo sorológico de anticorpos contra vírus em cracídeos. A partir dos resultados obtidos, não é possível afirmar que os vírus testados tenham importância na indução de doenças nessas aves. Contudo, o alto título de anticorpos contra o IBDV em alguns indivíduos e o histórico prévio de enfermidades causadas pelo ARV em outras espécies de aves silvestres podem ser vistos, no mínimo, como um alerta para os profissionais que trabalham com cracídeos.

\section{AGRADECIMENTOS}

Os autores agradecem à Fundação de Amparo à Pesquisa do Estado do Rio Grande do Sul (FAPERGS) (Processo 0410512), pelo financiamento, e à Coordenação de Aperfeiçoamento de Pessoal de Nível Superior (CAPES), pela bolsa de Mestrado concedida ao primeiro autor. 


\section{REFERÊNCIAS}

CAVANAGH, D.; NAQI, S.A. Infectious bronchitis. In: CALNEK, B.W. et al. Diseases of poultry. Iowa State: Blackwell, 2003. V.1, cap 3, p.101-119.

CLERC, M.G. et al. Serological survey of the king penguin, Aptenodytes patagonicus, in Crozet Archipelago for antibodies to infectious bursal disease, influenza A and Newcastle disease viruses. Polar Biology, v.25, n.4, p.316-319, 2002. Disponível em: <http://www.springerlink.com/content/dwv1ffr3rpcy9cuu/> . Acesso em: 25 nov. 2008. doi: 10.1007/s00300-001-0346-7.

DOCHERTY, D.E. American woodcock (Scolopax minor) mortality associated with a reovirus. Avian Diseases, v.38, n.4, p.899-904, 1994.

EVÊNCIO, J.N. Galliformes (mutum, jacu, jacutinga, aracuã, uru). In: CUBAS, Z.S.et al. Tratado de animais selvagens: medicina veterinária. São Paulo: Roca, 2006. p.169-184.

GOUVEA, V.; SCHNITZER, T.J. Pathogenicity of avian reoviruses: examination of six isolates and a vaccine strain. Infection and Immunity, v.38, p.731-738, 1982.

HOLLMEN, T. et al. Isolation and characterization of a reovirus from common eiders (Somateria mollissima) from Finland. Avian Diseases, v.46, n.2, p.478-484, 2002. Disponível em: <http://www.bioone.org/doi/full/10.1637/00052086(2002)046\%5B0478\%3>. Acesso em: 25 nov. 2008. doi: 10.1637/0005-2086(2002)046[0478:IACOAR]2.0.CO;2.

HUKKANEN, R.R. et al. Avipox sp. in a colony of graycrowned rosy finches (Leucosticte tephrocotis). Comparative Medicine, v.53, n.5, p.548-552, 2003.

LUKERT, P.D.; SAIF, Y.M. Infectious bursal disease. In: CALNEK, B.W. et al. Diseases of poultry. Iowa State: Blackwell, 2003. V.1, cap.6, p.161-179.

LÜSCHOW, D. et al. Differentiation of avian poxvirus strains on the basis of nucleotide sequences of $4 \mathrm{~b}$ gene fragment. Avian Diseases, v.48, n. 3, p.453-462, 2004. Disponível em: <http:/ /www.bioone.org/doi/full/10.1637/7111>. Acesso em: 25 nov. 2008. doi: $10.1637 / 711$.

NIBERT, M.L.; SCHIFF, L.A. Reoviruses and their replication. In: KNIPE, D.M.; HOWLEY, P.M. Fields virology. Philadelphia: Lippincott Williams \& Wilkins, 2001. p.16791728.

REED, W.M.; JACK, S.W. Quail bronchits. In: CALNEK, B.W. et al. Diseases of poultry. Iowa State: Blackwell, 2003. V.1, cap.3, p.248.

ROMERO, C.H. Manual técnico de diagnóstico virológico em patologias de aves. Concórdia: Embrapa Suínos e Aves, 1986. 130 p. (Manual técnico).

SANTOS, H.F. et al. Anticorpos contra vírus em galinhas de terreiro do Estado do Rio Grande do Sul, Brasil. Ciência Rural, v.38, n.7, p.1932-1937, 2008. Disponível em: < http:// www.s cielo.br/s cielo.ph p ? pid=S 0103 $84782008000700020 \&$ script $=$ sci_abstract $\&$ tlng $=$ pt $>$. Acesso em: 28 nov. 2008. doi: 10.1590/S0103-84782008000700020.

SICK, H. Ornitologia brasileira. Rio de Janeiro: Nova Fronteira, Rio de Janeiro, 1997. 827p.

TRAVIS, E.K. et al. Hematology, serum chemistry, and serology of galápagos penguins (Spheniscus mendiculus) in the Galápagos Islands, Ecuador. J ournal of Wildlife Diseases, v.42, n.3, p.625-632, 2006. Disponível em: <http://www.jwildlifedis.org/ cgi/content/ full/42/3/625>. Acesso em: 28 nov. 2008.

TRIPATHY, D.N.; REED, W.M. Pox. In: CALNEK, B.W. et al. Diseases of poultry. Iowa State: Blackwell, 2003. V.1, cap.9, p.253 - 269.

UHART, M.M. et al. Hematology, plasma biochemistry, and serosurvey for selected infectious agents in southern giant petrels from Patagonia, Argentina. Journal of Wildlife Diseases, v.39, n.2, p.359-365, 2003. Disponível em: <http:// www.jwildlifedis.org/cgi/content/abstract/39/2/359>. Acesso em: 28 nov. 2008. 